\title{
ON A NEW GENUS AND A NEW SPECIES OF EULOPHIDAE (HYMENOPTERA: CHALCIDOIDEA) FROM THE PADDY FIELDS OF SOUTHERN INDIA
}

\author{
T.C. Narendran ${ }^{1,2}$, P. Girish Kumar ${ }^{1,4}$, S. Santhosh ${ }^{1}$ and P.A. Sinu ${ }^{3}$ \\ ${ }^{1}$ Systematic Entomology Laboratory, Department of Zoology, University of Calicut, Kerala 673635, India \\ ${ }^{3}$ Ashoka Trust for Research in Ecology and Environment (ATREE), No. G 59, $5^{\text {th }}$ A Main Road, Hebbal, Bangalore, Karnataka 560024, India \\ Email: ${ }^{2}$ drtcnarendran@yahoo.com; ${ }^{4}$ k_p_girish@yahoo.co.in
}

\begin{abstract}
A new genus viz. Kiggaella Narendran with the type species Kiggaella oryzae Narendran sp. nov. is described from the paddy fields of Karnataka, India. It resembles the genus Minotetrastichus Graham in general appearance but differs from it in having scutellum without submedian groove, forewing more than $3 x$ as long as broad and one of the central setae much larger than any of the remaining ones.
\end{abstract}

\section{KEYWORDS}

Hymenoptera, Chalcidoidea, Eulophidae, Kiggaella gen nov., Kiggaella oryzae sp. nov., Karnataka, India.

\section{AbBreviations}

DZUC - Department of Zoology, University of Calicut; F1-F3 - Funicular segments 1to3; MV - Marginal vein; $\mathrm{OOL}$ - Ocellocular distance; PMV - Postmarginal vein; POL - Postocellar distance; SMV - Submarginal vein; STV - Stigmal vein

\section{INTRODUCTION}

Rice crop is often attacked by several insect pests in South and Southeast Asia. Many parasitoids belonging to parasitic Hymenoptera have been recorded from rice pests (Pathummal Beevi et al., 2000; Konishi et al., 2004). Some of these parasitoids may prove useful in future biocontrol programmes against these pests. In this paper we record and describe a genus and species of Tetrastichinae of Eulophidae, hitherto undescribed. It did not fit to any of the genera of Eulophidae dealt by Subba Rao and Hayat (1985), Boucek (1988), Graham (1991), La Salle (1994), Schauff et al. (1997) or any other genera listed by Noyes (2004). The type specimens are deposited in the collections of Systematic Entomology Laboratory, Department of Zoology, University of Calicut (DZUC)

\section{Kiggaella Narendran gen. nov.}

Type species: Kiggaella oryzae Narendran sp. nov.

\section{Etymology}

Named after the locality Kigga of Karnataka state, India.

\section{Diagnostic features}

Head partly collapsing; eye convergent to inner side; antennal toruli situated above lower ocular line, nearer to eye than to each other; frontal fork absent; antennal formula 11233; scape not exceeding vertex, clava without apical spine or spicule; occiput not margined; clypeus not delimited, lower clypeal margin clearly bilobed; mandibles bidentate; malar sulcus distinct; mesosomal dorsum smooth and shiny; mesoscutum with three pairs of adnotaular setae; axillae advanced anteriorly; scutellum with submedian grooves or lines with three pairs of setae (median pair worn out but pits distinct); scutellum a little shorter than mesoscutum; forewing length a little more than $3 \mathrm{x}$ as long as broad; SMV with two dorsal setae; propodeum smooth with median carina; propodeal spiracle exposed, separated from hind margin of metanotum by less than its diameter; one of the cercal setae very long and not subequal to any other cercal setae. Body metallic green with lower part of head, posterior marginal area of lateral panel of pronotum and legs (except hind coxae) pale whitish-yellow.

\section{Discussion}

This new Genus comes to Minotetrastichus Graham in the key to species of Graham (1991) but clearly differs from it in having: (i) scutellum without submedian grooves or lines (in Minotetrastichus scutellum with submedian grooves); (ii) Scutellum with three pairs of setae (2 pairs only in Minotetrastichus); (iii) forewing clearly more than $3 \mathrm{x}$ as long as broad (in Minotetrastichus forewing never 3x as long as broad); (iv) one of the cercal setae very long, sinuate and not subequal to any of the other cercal setae (in Minotetrastichus cercal setae is not so lengthy)

Graham (1991) states that in some groups of Aprostocetus Westwood the submedian grooves on scutellum is absent but in such cases body is black and non metallic and clava with apical seta and tip of hypopygium situated at not more than $0.6 x$ length of gaster. Though in the nature of cercal setae, lower clypeal margin and antenna, this genus comes near Aprostocetus, differs in the combination of characters mentioned under diagnosis of the genus given above.

\section{Kiggaella oryzae Narendran sp. nov.}

(Figs. 1-6)

\section{Material examined}

Holotype: Female, 16.x.2003, Kigga (75013'-15'E \& 13028'-30'N), Sringeri, Karnataka, coll. P.A. Sinu, MoEF 4371(DZUC).

Paratypes: 6 Females (MoEF 4374 - MoEF 4379) and 2 Males (MoEF $4372 \&$ MoEF 4373) of same collection data of Holotype;

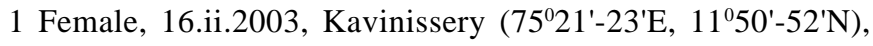
Kannur Dt., Kerala, coll. T.C. Narendran \& party (MoEF 318) (All types are deposited in DZUC).

\section{Etymology}

Species name is after Rice (Oryza sativa L. (Family: Poaceae)) since the specimens were obtained from paddy field.

(C) Zoo Outreach Organisation; www.zoosprint.org 


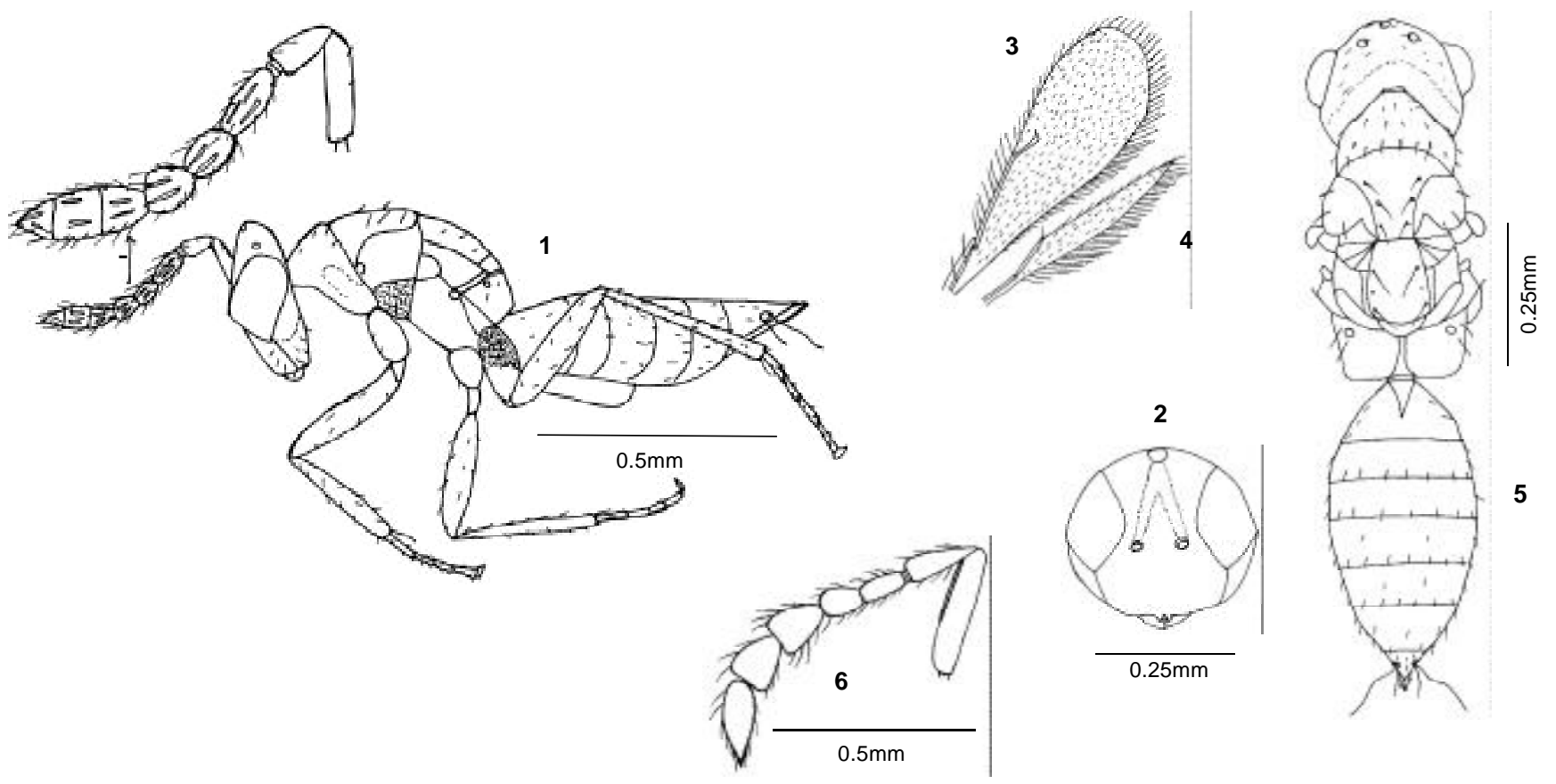

Figures 1-6. Kiggaella oryzae Narendran sp. nov. (1-5 Female).

1 - Body profile; 2 - Head front view; 3 - Fore wing; 4 - Hind wing; 5 - Body dorsal view; 6 - Male antenna

Holotype: Female. Length 1.2mm. Metallic green with slight darkish tinge; lower frons, gena and all legs pale yellow with basodorsal part of hind coxa concolourous with mesosoma; eye and ocelli dark brown; wings hyaline with veins pale yellow, pubescence pale white.

Head: Partly collapsing; width in anterior view a little wider than its length (69:64); width in dorsal view 1.42x its maximum length; eye (Fig. 2) convergent towards frons; eye height in profile $2.1 \mathrm{x}$ length of malar space; malar sulcus distinct, not curved, without a basal fovea below eye; occiput not margined but yellow colour separates head as upper and lower halves (Fig. 5); POL a little more than 1.6x OOL. Relative length: width of antennal segments: scape - 19:6; pedicel - 15:7; F1 - 16:7; F2 - 12:8.5; F3 - 12:10; clava - 29:9; mandible weakly bidentate.

Mesosoma: Smooth and shiny; pronotum conical, without a cross ridge or carina; mesoscutum with three pairs of adnotaular setae; axillae a little advanced anteriorly; scutellum longer than wide; dorsellum not medially divided; propodeum without plicae or costula; prepectus longer than tegula, weakly reticulate; metanotum reaching hind wing base. Fore wing with relative length of veins: SMV - 21; MV - 36; PMV - absent; STV - 11; hind wing with a basal stalk.

Metasoma: Petiole hardly visible; gaster a little longer than mesosoma, with a basal fovea on first tergite; one of the cercal setae much longer than any of the remaining ones, sinuate.

Male: Similiar to female except antennal formula 11241, funicular segments (Fig. 6) yellowish-white with side margins and apical margins pale brown; ventral side of scape with a distinct ventral plaque on anterior half.

Host: Unknown.

Biology: Unknown.

\section{REFERENCES}

Boucek, Z. (1988). Australasian Chalcidoidea (Hymenoptera). A Biosystematic Revision of Fourteen Families, with a Reclassification of Families. CAB International, Wallingford, 832pp.

Graham, M.W.R.de V. (1991). A reclassification of the European Tetrastichinae (Hymenoptera: Eulophidae). Revision of the remaining Genera. Memoirs of the American Entomological Institute (Gainesville) 49: 1-322.

Konishi, K., T.C. Narendran, T. Imamura and P. Visarathanonth (2004). Chalcididae (Hymenoptera) from rice stores in Thailand, with description of two new species. Entomological Science 7: 31-38.

LaSalle, J. (1994). North American Genera of Tetrastichinae. (Hymenoptera: Eulophidae). Journal of Natural History 28:109-236.

Noyes, J.S. (2004). Universal Chalcidoidea Database. http:// www.nhm.ac.uk/ entomology/chalcidoids/chalcididae.html.

Pathummal Beevi, S., K.R. Lyla and T.C. Narendran (2000). Hymenopteran diversity in single and double cropped rice ecosystems in Kerala, India. International Rice Research Notes 25(1): 20-21.

Schauff, M.E., J. La Salle and L.D. Coote (1997). Eulophidae, pp.327-429. In: Annotated Key to the Genera of Nearctic Chalcidoidea (Hymenoptera). National Research Council of Canada Monograph Publishing Program, 794pp. Subba Rao, B.R. and M. Hayat (1985). The Chalcidoidea (Insecta: Hymenoptera) of India and the adjacent countries. Oriental Insects 19: 163310.

\section{ACKnowledgement}

We are grateful to the Ministry of Environment and Forests, New Delhi for a grant to undertake a research project on the systematics of Eulophidae. We also record our thanks to the authorities of the University of Calicut for facilities. 